\title{
Article \\ Induction of Metabolic Changes in Amino Acid, Fatty Acid, Tocopherol, and Phytosterol Profiles by Exogenous Methyl Jasmonate Application in Tomato Fruits
}

\author{
Silvia Leticia Rivero Meza ${ }^{1}$, Eric de Castro Tobaruela ${ }^{1}{ }^{\mathbb{D}}$, Grazieli Benedetti Pascoal $^{2}$, \\ Hilton César Rodrigues Magalhães ${ }^{3}$ (D), Isabel Louro Massaretto ${ }^{1}$ and Eduardo Purgatto ${ }^{1, *}$ \\ 1 Food Research Center, Department of Food Science and Experimental Nutrition, \\ Faculty of Pharmaceutical Sciences, University of São Paulo (USP), Av. Prof. Lineu Prestes 580, bl 14, Butantã, \\ São Paulo 05508-000, SP, Brazil; silvialrmeza@gmail.com (S.L.R.M.); erictobaruela@gmail.com (E.d.C.T.); \\ isabelmassaretto@gmail.com (I.L.M.) \\ 2 Faculty of Medicine, Federal University of Uberlândia (UFU), Av. Pará, 1720, bl 2U, Umuarama, \\ Uberlândia 38405-320, MG, Brazil; grazi.nutri13@gmail.com \\ 3 Embrapa Agroindústria Tropical, Rua Dra. Sara Mesquita 2270, Fortaleza 60511-110, CE, Brazil; \\ hilton.magalhaes@embrapa.br \\ * Correspondence: epurgatt@usp.br; Tel.: +55-11-30911480
}

Citation: Meza, S.L.R.; de Castro Tobaruela, E.; Pascoal, G.B.;

Magalhães, H.C.R.; Massaretto, I.L.; Purgatto, E. Induction of Metabolic Changes in Amino Acid, Fatty Acid, Tocopherol, and Phytosterol Profiles by Exogenous Methyl Jasmonate Application in Tomato Fruits. Plants 2022, 11, 366. https://doi.org/ $10.3390 /$ plants 11030366

Academic Editors: Emilia Wilmowicz and Agata Kućko

Received: 9 December 2021

Accepted: 24 January 2022

Published: 28 January 2022

Publisher's Note: MDPI stays neutral with regard to jurisdictional claims in published maps and institutional affiliations.

Copyright: (C) 2022 by the authors. Licensee MDPI, Basel, Switzerland. This article is an open access article distributed under the terms and conditions of the Creative Commons Attribution (CC BY) license (https:// creativecommons.org/licenses/by/ $4.0 /)$.

\begin{abstract}
Methyl jasmonate hormone can stimulate the production of several metabolites responsible for improving fruit quality and nutritional attributes related to human health. In this context, efforts to manipulate tomatoes, such as using hormonal treatment to increase metabolite levels essential to plant growth and human nutrition, have received considerable attention. The aim of this study was to show the impact of metabolic profile on fruit quality and nutritional properties under exogenous methyl jasmonate during fruit ripening. The treatments were performed using $100 \mathrm{ppm}$ of methyl jasmonate and $100 \mathrm{ppm}$ of gaseous ethylene over $24 \mathrm{~h}$. Ethylene emission, fruit surface color and metabolomics analysis were measured at 4,10, and 21 days after harvest, considering the untreated fruits as control group. Methyl jasmonate induced the production of amino acids-mainly glutamine, glutamic acid and $\gamma$-aminobutyric acid (at least 14-fold higher) — and fatty acids — mainly oleic, linoleic, and linolenic acids (at least three-fold higher than untreated fruits); while exogenous ethylene predominantly affected sugar metabolism, increasing the levels of fructose, mannose and glucose to at least two-fold that levels in the untreated fruits. Additionally, methyl jasmonate significantly affected secondary metabolites, inducing by at least $80 \%$ the accumulation of $\alpha$-tocopherol and $\beta$-sitosterol in fully ripe fruits. Our results suggest that the postharvest application of the hormone methyl jasmonate can contribute to the sensory characteristics and increase the nutritional value of the fruits since important changes related to the tomato metabolome were associated with compounds responsible for the fruit quality and health benefits.
\end{abstract}

Keywords: jasmonate; postharvest management; metabolic changes; tomato fruits; nutritional value; GC-MS

\section{Introduction}

Tomato (Solanum lycopersicum) is a valuable fruit crop with economic and nutritional importance. Tomatoes present massive health-promoting compounds such as phenolic compounds, carotenoids, tocopherols and vitamins, which have important biological effects, including antimicrobial, anti-allergenic, anti-inflammatory, antithrombotic, cardioprotective, vasodilatory and antioxidant properties [1]. Several important changes occur during tomato fruit ripening which decisively affect fruit quality and nutritional value. However, recent research has demonstrated that early fruit development plays an essential role in quality parameters such as the accumulation of primary metabolites, including sugars and organic acids [2]. 
During fruit evolution, morphological stages are evidenced in the tomato fruits, including immature, mature green, breaker, pink and red ripe fruits, which are characterized by the transition from incomplete photosynthetic to complete heterotrophic metabolism [2]. This complex process are coordinated by several phytohormones such as auxins, cytokinins, gibberellins, abscisic acid, salicylic acid, brassinosteroids, ethylene and jasmonates [3]. In addition, recently studies have shown the influence of nitric oxide in controlling plant responses, including the transduction of previously mentioned phytohormones [4,5]. For instance, nitric oxide and ethylene operate antagonistically during the physiological process [6]. Nitric oxide down-regulates fruit ethylene synthesis, suppressing growth, increasing firmness and delaying ripening in tomato fruits [7,8]. In addition, nitric oxide demonstrates that it is a signaling component in MeJA-induced stomatal closure in Arabidopsis guard cells [9].

Methyl jasmonate acts as an important growth regulator and protects tomato plants by inducing biological and biochemical changes [3]. The accumulation of metabolites in plants is associated with the application of exogenous methyl jasmonate, which can stimulate fruit ripening by increasing ethylene production $[10,11]$. Methyl jasmonate can activate the expression of 1-aminocyclopropane-1-carboxylic acid synthase and 1-aminocyclopropane-1-carboxylic acid oxidase in unripe tomatoes, increasing enzymatic activity and ethylene production [12].

Previous studies have demonstrated that the use of exogenous methyl jasmonate can induce secondary metabolism in plant cells and antioxidant capacity, improving fruit quality [13,14]. However, studies on the effect of methyl jasmonate on the tomato metabolome are mainly related to the production of phenolics, carotenoids, and volatile compounds [10,15]. Minimal knowledge is available concerning a wide variety of metabolites that methyl jasmonate affects during ripening, such as the primary and secondary metabolism. Primary metabolites such as sugars, organic acids, and amino acids are the main classes of chemical compounds responsible for tomato fruit quality, affecting consumers' sensorial perception [16]. Sugars and organic acids offer sweetness and acid balance, producing a desirable flavor, and amino acids provide taste, such as glutamic acid (umami taste), valine (bitter taste), proline, and serine (sweetness) [17]. Conversely, secondary metabolites play an important role in health promotion, as they are important nutrients for humans. Tocopherols are important antioxidants that scavenge lipid peroxyl radicals and reactive oxygen species in lipophilic environments [18]. Phytosterols such as $\beta$-sitosterol are associated with reducing LDL cholesterol and total cholesterol [19], while carotenoids provide the precursor of vitamin A and antioxidant properties [17]. Additionally, some metabolites, such as phenylalanine, tyrosine, tryptophan, linoleic acid, linolenic acid, and lycopene, play important roles as aroma precursors during fruit maturation [20,21].

Thus, the enhancement of fruit quality and the nutritional characteristics of fruits during ripening are commercially essential for horticultural production and are associated with human health. For this reason, the use of methyl jasmonate as an alternative to increasing the production of metabolites can contribute to the sensory and nutritional properties of the crops. Additionally, methyl jasmonate is generally recognized as safe (GRAS) by the Food and Drug Administration, allowing its potential use postharvest. This study investigated the impact of postharvest methyl jasmonate treatment on a wide range of metabolites, including primary and secondary metabolites, of tomato fruits (Solanum lycopersicum L. cv. Grape), compared to ethylene treatment and an untreated fruits.

\section{Results and Discussion}

\subsection{Ethylene Emission and Fruit Surface Color Were Affected by Methyl Jasmonate}

The untreated group achieved the breaker stage at $4 \mathrm{DAH}$, red stage at $10 \mathrm{DAH}$, and final postharvest stage at $21 \mathrm{DAH}$. Tomato fruits treated with phytohormones and untreated fruits are shown in Figure 1. Treatments with ethylene and methyl jasmonate accelerated fruit ripening changes to a greater extent than CTRL. The CTRL group showed the peak of ethylene emission at $10 \mathrm{DAH}$, while ETHY and MeJA showed corresponding peaks at $9 \mathrm{DAH}$. Interestingly, the level of ethylene emission in MeJA at 9 DAH was at least two-fold higher than that observed in the other groups (Figure 2A). This behavior 
can be associated with the stimulation of ethylene production in climacteric fruits by the exogenous methyl jasmonate [20].

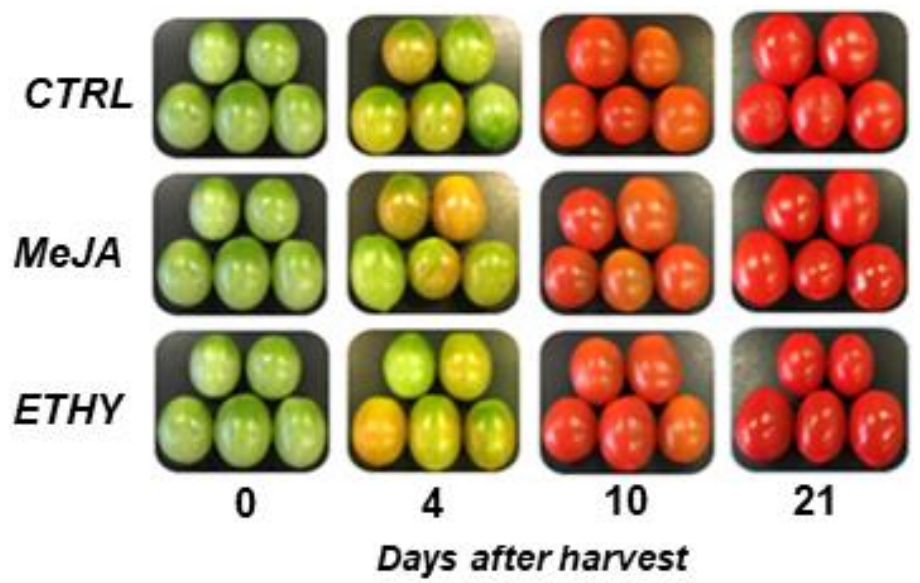

Figure 1. Representative images of tomatoes (Solanum lycopersicum L. cv. Grape) exposed to exogenous ethylene (ETHY) and methyl jasmonate (MeJA) compared to the control group (CTRL).

A

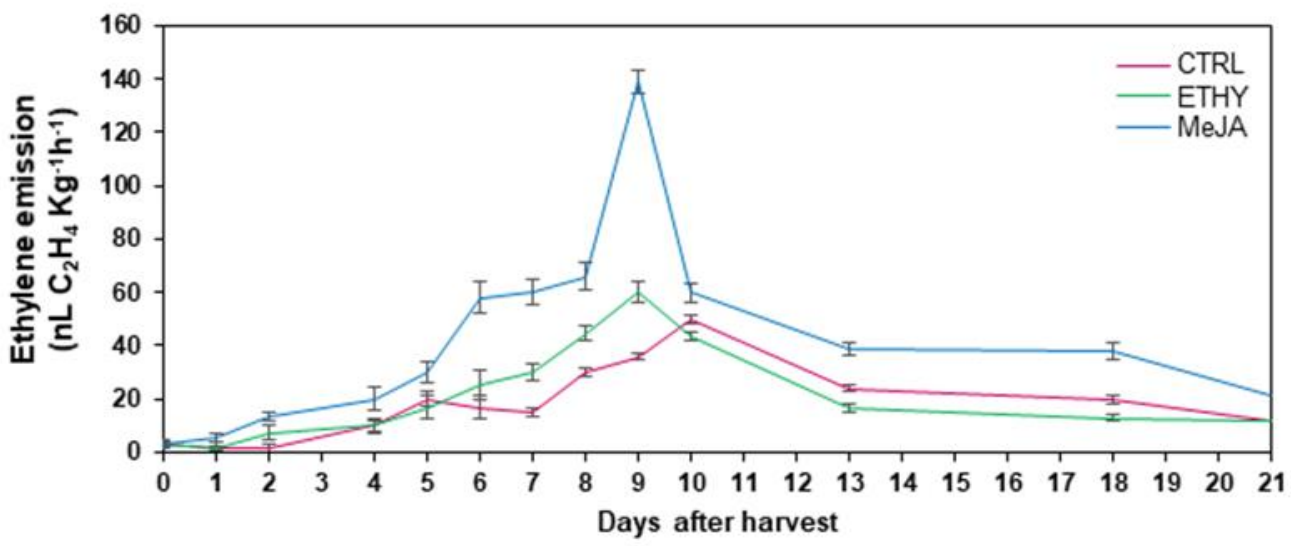

B

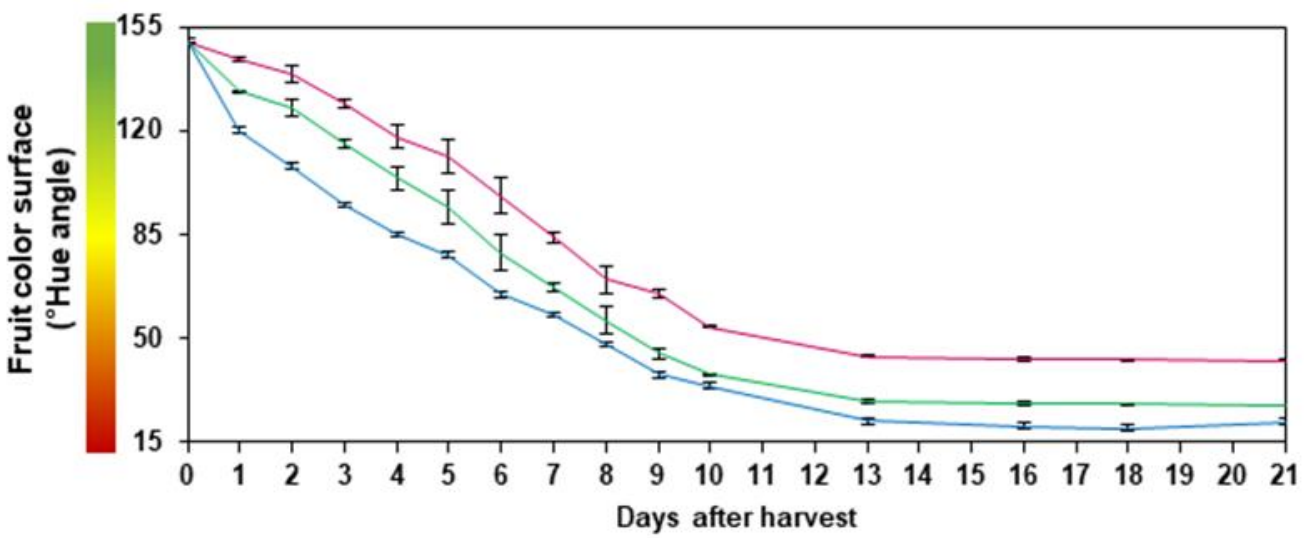

Figure 2. Ethylene emission (A) and fruit color (B) of tomato (Solanum lycopersicum L. cv. Grape) exposed to exogenous ethylene (ETHY) and methyl jasmonate (MeJA) compared to the control group (CTRL). Values are means \pm SD of four biological replicates of 10 fruits each.

The phytohormones promoted changes in the tomato surface color slightly faster than in CTRL. ETHY and MeJA first turned red, indicating that treated fruits had completely ripened at $9 \mathrm{DAH}$, while the CTRL fruits were fully ripe at $10 \mathrm{DAH}$ (Figure 2B). Treatment with ethylene can accelerate color changes in fruits due to its capacity to improve the transcription of mRNAs encoding enzymes, such as phytoene synthase, related to carotenoid 
production. Methyl jasmonate can also induce carotenoid metabolism in tomatoes [15,22]. Thus, analysis of ethylene emission and surface color revealed that both hormones might play an important role in regulating the carotenoid pathway and lycopene accumulation, accelerating these events in the ripening process.

\subsection{Impact of Methyl Jasmonate on Primary Metabolites in Tomatoes}

Primary metabolites are major components of fruit quality, and related metabolisms are considered crucial for plant growth [23]. Increasing understanding of this process could facilitate developing future strategies for manipulating fruit metabolism. The levels of sugars (fructose, sucrose, and glucose), organic acids (citric and malic acids), amino acids (glutamic acid, $\gamma$-aminobutyric acid (GABA), aspartic acid, and aromatic amino acids), and fatty acids (linoleic and linolenic acids) are essential to define the quality of ripe fruits, as they are responsible for the taste of the fruit and used for the synthesis of aroma compounds $[20,21]$. The sugar metabolism was affected by the ethylene, whereas organic acids, amino acids, and the fatty acid metabolism were impacted mainly by methyl jasmonate (Figure 3). Ethylene evidently modified sugar metabolism during ripening, showing a higher tendency to accumulate fructose, mannose, glucose, sucrose, glucaric acid, allose, gulose, ribose, myo-inositol, and arabinofuranose (Figure 3A). Changes in sugar metabolism in tomato fruits can be related to the interaction of ethylene and nitric oxide. The accumulation of sugars, amino acids and organic acids in fleshy fruits has been associated with action of the nitric oxide, which are important for determining fruit quality as well as flavor and Brix [24].

A

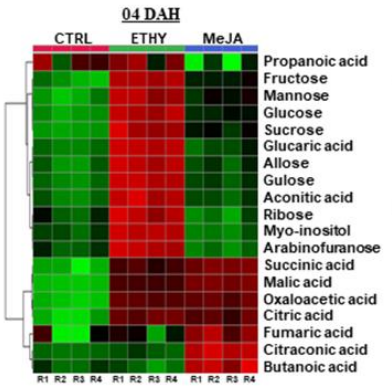

B
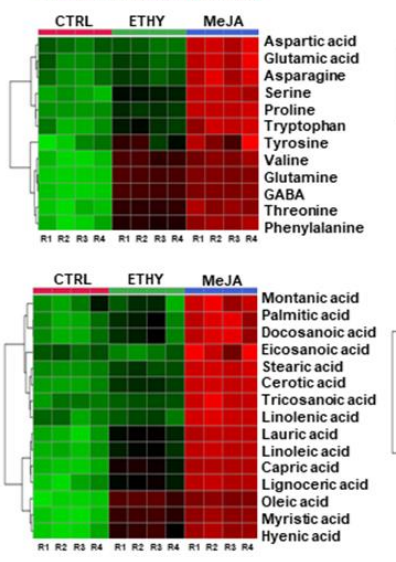
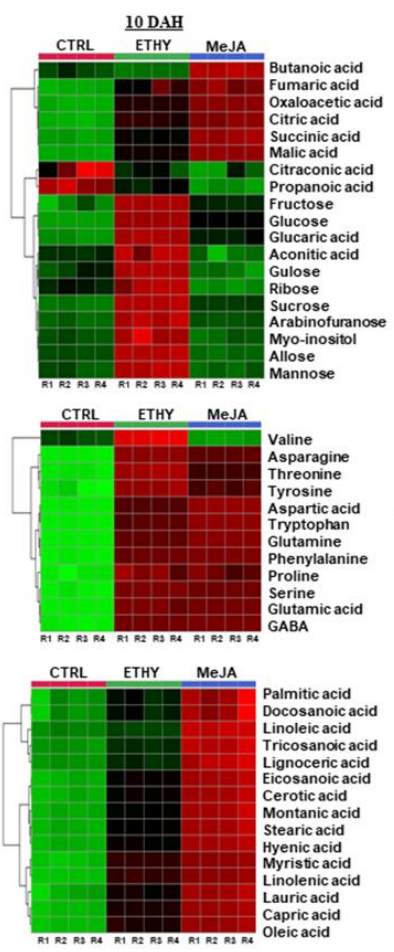
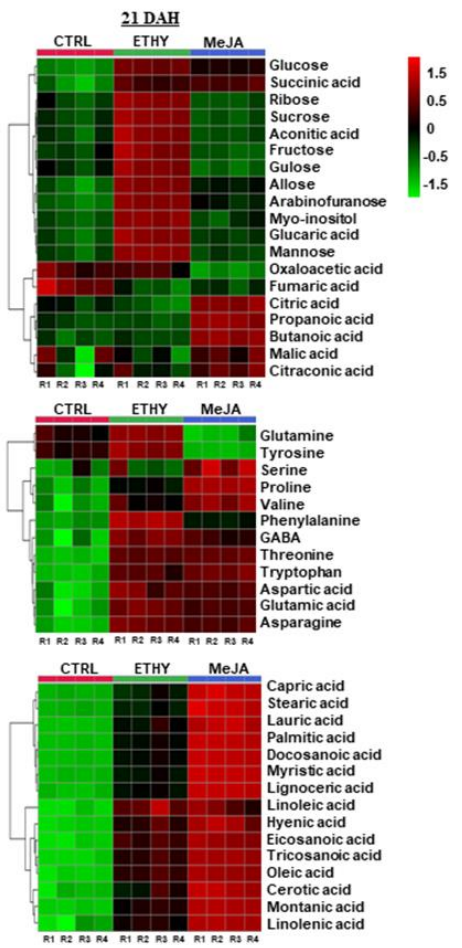

Figure 3. Primary metabolites in tomato (Solanum lycopersicum L. cv. Grape) exposed to exogenous ethylene (ETHY) and methyl jasmonate (MeJA) compared to the control group (CTRL). Relative contents of sugars and organic acids (A), amino acids (B), and fatty acids (C). Heatmap analysis representing the major sources of variability. Color scale represents the variation in the relative concentration of compounds, from low (green) to high (red) contents. Relative contents are represented by the normalized area values of each metabolite. Values are means \pm SD of four biological replicates of 10 fruits each. Days after harvest (DAH); biological replicates ${ }^{\circledR}$.

Nitric oxide plays an important role in the synthesis of ethylene by down-regulating it production and, consequently, delaying fruit ripening by acting as a repressor of ACS and 
ACO transcript accumulation and enzymatic activity [6,8]. The crosstalk between ethylene and nitric oxide may be associated to the $\mathrm{H}_{2} \mathrm{~S}$ and melatonin mediation during fruit ripening [6]. Nitric oxide affects different metabolic pathways, acting early on molecular processes that are responsible for sensory and nutritional quality [24]. For example, several of the genes linked with fruit quality characteristics are modulated in response to nitric oxide in sweet pepper (Capsicum annuum) [5]. However, studies related to reactive nitrogen species metabolism and its effects during the ripening of tomato fruit are still scarce $[5,24]$.

The levels of fructose, mannose, and glucose in fruits treated with ethylene were at least two-fold higher than those in the CTRL group. The total sugar level reflected the changes in the most abundant sugars identified as fructose, sucrose, and glucose (Table S1).

However, methyl jasmonate showed a tendency to increase organic acids; the highest levels of citric, succinic, malic, oxaloacetic, and fumaric acids were detected at $10 \mathrm{DAH}$ (Figure 3A). The levels of citric and malic acids were increased eight-fold, while succinic and oxaloacetic acids were increased to four-fold the levels in the CTRL at 10 DAH. Citric, succinic, and malic acids were essential to the total organic acid level (Table S1). The remarkable increase in ethylene emission by methyl jasmonate at 9 DAH (Figure 2A) can affect the respiration of tomato fruits, which may explain the increase in the level of organic acids, predominantly in intermediates of the tricarboxylic acid (TCA) cycle, detected mainly at $10 \mathrm{DAH}$.

Moreover, methyl jasmonate hormone showed a high capacity to accumulate amino acids in the fruits (Figure 3B). Glutamine, glutamic acid, and GABA, free amino acids involved in the GABA shunt, presented levels that were 16-, 2-, and 27-fold higher at 4 DAH and 29-, 27-, and 14-fold higher at $10 \mathrm{DAH}$, respectively, compared with untreated fruits. Glutamine is known as a relevant form of nitrogen transport in tomatoes, while GABA is a four-carbon non-protein amino acid that has gained considerable attention as a healthpromoting functional compound [25]. Thus, the function of free amino acids implicated in the GABA shunt in front of methyl jasmonate treatment deserve more attention owing to their significance in ripening and nutritional quality of fruits. Aromatic amino acids involved in the shikimate pathway were also positively impacted by the postharvest treatment with methyl jasmonate, mainly at $10 \mathrm{DAH}$. The production of tyrosine increased three-fold, while phenylalanine and tryptophan increased to levels 29-fold higher than those in the CTRL at 10 DAH. The total amino acid level was represented mainly by glutamic and aspartic acids (Table S1).

The fatty acid profile was significantly affected by the methyl jasmonate hormone. Figure 3C clarifies the tendency of methyl jasmonate to increase the fatty acid metabolism compared with ETHY and CTRL. MeJA showed at least two-fold increases in capric, lauric, myristic, palmitic, stearic, eicosanoic, docosanoic, tricosanoic, lignoceric, cerotic, and montanic acids compared to the values found for untreated fruits during ripening. Unsaturated fatty acids, oleic, linoleic, and linolenic acids, were most impacted by the methyl jasmonate, with their levels increasing by three-fold to four-fold. This is interesting, as they are considered valuable nutrients and important to fruit quality [26]. Palmitic, capric, and eicosanoic acids were essential to the total level of saturated fatty acids and linoleic and oleic acids to the total level of unsaturated fatty acids (Table S1).

\subsection{Impact of Methyl Jasmonate on Secondary Metabolites in Tomatoes}

Carotenoids, tocopherols, and phytosterols play important roles in health promotion, contributing to the antioxidant capacity of tomato fruits [24]. Lycopene, $\beta$-carotene, and lutein were increased by both phytohormones. Major lycopene, $\beta$-carotene, and lutein contents $\left(1115.3,10.16\right.$, and $5.25 \mu \mathrm{g} \mathrm{g}^{-1} \mathrm{FW}$, respectively) were detected at 21 DAH in ETHY. The interaction between ethylene and nitric oxide lead not only to antagonism, but also to the promotion of post-translational modifications of antioxidant enzymes. This process results in changes in chlorophyll degradation, lipid peroxidation, pericarp browning, anthocyanin and flavonoid biosynthesis and antioxidant capacity [6]. Nonetheless, the contrary performance was noted at $10 \mathrm{DAH}$ whereas higher lycopene, $\beta$-carotene, and 
lutein contents were revealed in MeJA $\left(742.5,7.25\right.$, and $4.43 \mu \mathrm{g} \mathrm{g}^{-1} \mathrm{FW}$, respectively; Figure $4 \mathrm{~A}$ and Supplementary Table S2). The acceleration of the maturation process evidenced by fruit surface color in ETHY and MeJA (Figure 2B) can be directly correlated to the accumulation of carotenoids, mainly lycopene, compared with the CTRL. Lycopene mainly represented the total carotenoid levels. Ethylene and methyl jasmonate increased lycopene by $40 \%$ and $50 \%$, respectively, at $10 \mathrm{DAH}$ and $100 \%$ and $40 \%$, respectively, at 21 DAH (Figure 4A).

A
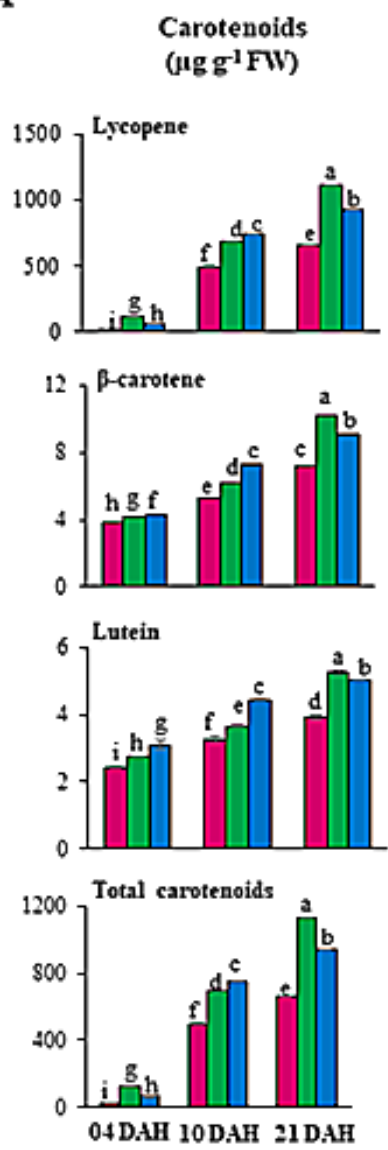

B
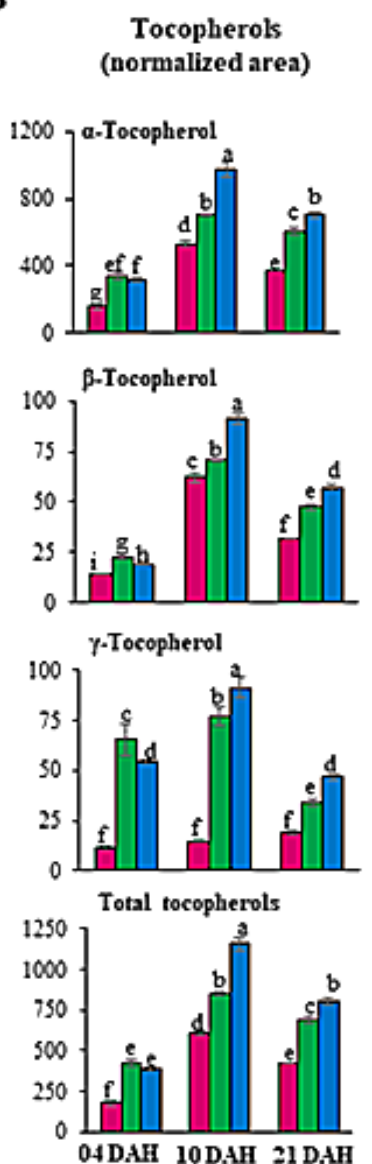

C
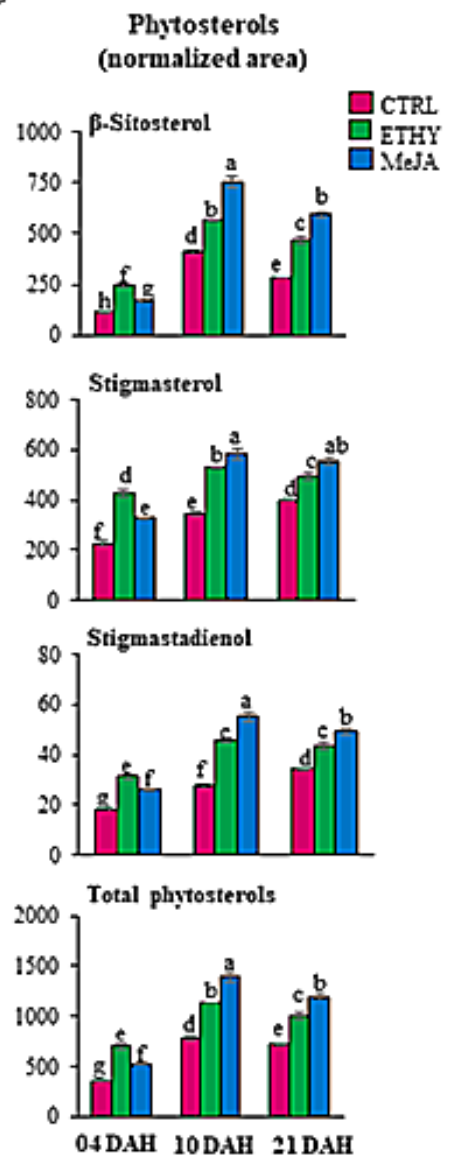

Figure 4. Secondary metabolites in tomato (Solanum lycopersicum L. cv. Grape) exposed to exogenous ethylene (ETHY) and methyl jasmonate (MeJA) compared to the control group (CTRL). Contents of carotenoids in $\mu \mathrm{g} \mathrm{g}^{-1} \mathrm{FW}(\mathbf{A})$, relative contents of tocopherols (B), and phytosterols (C). Heatmap analysis representing the major sources of variability. Color scale represents the variation in the relative concentration of compounds, from low (green) to high (red) contents. Relative contents are represented by the normalized area values of each metabolite. Values are means \pm SD of four biological replicates of 10 fruits each. Different letters indicate statistically significant differences $(p<0.05)$. Days after harvest (DAH).

Tocopherols and phytosterol profiles were affected mainly by methyl jasmonate during ripening (Figure 4B, C). The highest levels of $\alpha-, \beta$-, and $\gamma$-tocopherol, $\beta$-sitosterol, stigmasterol, and stigmastadienol were observed at $10 \mathrm{DAH}$ in MeJA (Table S3). The production of $\alpha$-tocopherol, which represented the major source of tocopherol found in Grape tomato, was increased by $85 \%$ at 10 and $21 \mathrm{DAH}$ (Figure $4 \mathrm{~B}$ ); $\beta$-sitosterol and stigmasterol were important sources of phytosterols identified in tomato fruits. Exogenous methyl jasmonate hormone increased the levels of $\beta$-sitosterol and stigmasterol by $80 \%$ and $70 \%$, respectively, at $10 \mathrm{DAH}$, and by $100 \%$ and $40 \%$, respectively, at $21 \mathrm{DAH}$ (Figure $4 \mathrm{C}$ ).

The production of tocopherols, synthesized from phytyl diphosphate generated by geranylgeranyl diphosphate (GGPP) and homogentisic acid from the shikimate pathway [18] in 
red ripe fruits treated with methyl jasmonate, may be associated with the presence of aromatic amino acids involved in the shikimate pathway, such as phenylalanine, tryptophan, and tyrosin mainly at $10 \mathrm{DAH}$. Carotenoids and tocopherols share a similar precursor, GGPP, generated by the methylerythritol phosphate pathway. This metabolic interaction indicates that alterations in one of these may influence the biosynthesis of the other metabolite [18].

In both hormonal treatments, higher levels of tocopherol were detected at $10 \mathrm{DAH}$ and carotenoids at $21 \mathrm{DAH}$, indicating that the reduction in tocopherols is matched with a raise in carotenoids. This metabolic interaction suggests that modifications in carotenoid biosynthesis may impact affect the tocopherol level. However, a better comprehension of the accumulation of the mentioned compounds depends on deciphering the complexity of the isoprenoid metabolic network.

\subsection{Global Overview of Metabolic Changes Occurring in MeJA}

This work pointed out the potential of methyl jasmonate application to enhance the levels of primary and secondary metabolites in tomato fruits during ripening offthe-vine in order to improve their quality. However, it is important to highlight the changes in the quality and nutritional value of fruit ripening on the vine. Recent study showed the potential of methyl jasmonate pre-harvest application to increase several phenolic compounds in grapes, suggesting that this phytohormone can be used as elicitor to secondary metabolism [27]. In this context, methyl jasmonate has demonstrated the ability to stimulate the production of a wide variety of metabolites in tomatoes during ripening off-the vine. The entire metabolic pathways were constructed to observe the changes in primary and secondary metabolism in treated fruits compared to CTRL (Figure 5).
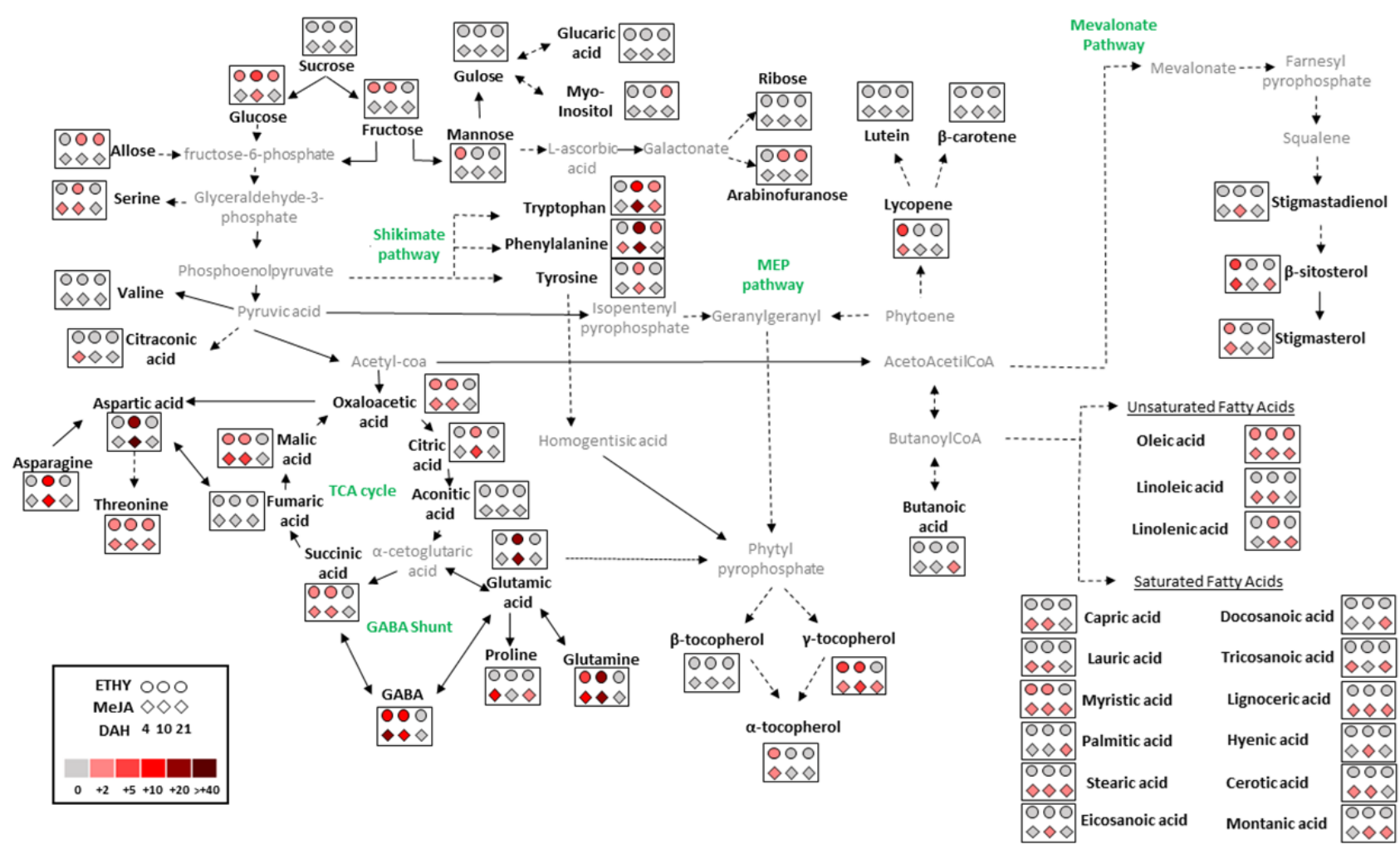

Figure 5. Metabolic changes in tomato (Solanum lycopersicum L. cv. Grape) exposed to exogenous ethylene (ETHY) and methyl jasmonate (MeJA) compared to the control group (CTRL). Data were normalized to CTRL. Metabolites presenting up- or down-regulation in each treatment exceeding two-fold compared to CTRL are shown. Color scale is used to display the different amounts of metabolites in terms of the fold change relative to the level in the appropriate control; $\gamma$-aminobutyric acid (GABA); tricarboxylic acid (TCA); methylerythritol phosphate (MEP); days after harvest (DAH). 
Exogenous methyl jasmonate mainly affected amino acids, fatty acids, tocopherols, and phytosterol profiles. Levels of aspartic acid, asparagine, and threonine were 55-, 12-, and 3-fold higher, respectively, whereas free amino acids, glutamine, glutamic acid, and GABA, increased 29, 27, and 14-fold, respectively, compared to CTRL at 10 DAH. The accumulation of GABA may be related to the largest contents of metabolites being involved in the GABA shunt, such as glutamic acid, succinic acid, and glutamine, mainly at 10 DAH. The increase in the production of asparagine and oxaloacetic acid levels by methyl jasmonate, mainly at $10 \mathrm{DAH}$, may be responsible for the increase in aspartic acid, reflected in its massive accumulation. Additionally, phenylalanine, tryptophan, and tyrosin were significantly affected by methyl jasmonate, mainly at $10 \mathrm{DAH}$, suggesting that aromatic acids may contribute to the accumulation of $\alpha$-tocopherol, which reached levels $85 \%$ higher than in untreated red fruits (Figure 4B). However, the highest levels of $\alpha$-tocopherol were observed after $10 \mathrm{DAH}$; levels of ethylene and methyl jasmonate hormones at $4 \mathrm{DAH}$ were double those found in untreated fruits (Figure 5). The content of $\gamma$-tocopherol contributed only $8 \%$ of the total tocopherol level, whereas $\gamma$-tocopherol was strongly impacted by methyl jasmonate, increasing its level sixfold compared with untreated fruits (Figure 5).

Both $\beta$-sitosterol and stigmasterol were essential sources of phytosterols identified in Grape tomato. Exogenous methyl jasmonate hormone increased the levels of $\beta$-sitosterol and stigmasterol by $80 \%$ and $70 \%$, respectively, at $10 \mathrm{DAH}$, and by $100 \%$ and $40 \%$, respectively, at 21 DAH (Figure 4C). Fruits treated with exogenous methyl jasmonate showed a strong tendency to accumulate metabolites during their ripening. Generally, the major contents of these metabolites were observed at 10 and $21 \mathrm{DAH}$. However, the same metabolites were drastically affected by methyl jasmonate at 4 DAH compared with CTRL, as observed for lycopene, $\alpha$ - and $\gamma$-tocopherol, $\beta$-sitosterol, and stigmasterol, which doubled their contents at the onset of ripening (Figure 5).

The accumulation of metabolites induced by methyl jasmonate treatment leads to acceleration of tomato ripening, which may be associated with the promotion of ethylene biosynthesis by jasmonate [28]. Several studies show the importance of jasmonate in the fruit ripening [29-31]. For instance, exogenous application of jasmonate results in increased ethylene production in tomato fruit [32,33]. However, the mechanism involving the increased expression of ethylene signaling genes promoted by jasmonate in tomato is still scarce. In apple fruits, it was observed that ethylene production induced by jasmonate is dependent on the expression of MdACS1 (ACC synthase gene involved in ethylene biosynthesis) and the expression of MdMYC2 (transcription factor involved in the jasmonate signaling pathway) was improved by methyl jasmonate treatment [28].

\section{Materials and Methods}

\subsection{Fruit Treatment}

Mature green tomatoes (Solanum lycopersicum cv. Grape; $n=1200$ ) were collected from a standard commercial greenhouse in Ibiúna ( $23^{\circ} 39^{\prime} 21^{\prime \prime}$ S; $47^{\circ} 13^{\prime} 22^{\prime \prime}$ W), São Paulo, Brazil, and transported on ice to the postharvest facilities. Aqueous sodium hypochlorite solution $(0.1 \%)$ was used for fruit sterilization for $15 \mathrm{~min}$. Four biological replicates were used, each comprising 100 fruits. Fruits were randomly separated into three groups $(n=400$ by group): (1) control group (CTRL), without treatment; (2) treated ethylene group (ETHY); and (3) treated methyl jasmonate group (MeJA). The treatments were performed using 100 ppm of gaseous ethylene and 100 ppm of methyl jasmonate (Sigma-Aldrich, Saint Louis, MO, USA), considering the final concentration in the gas phase. The methyl jasmonate was applied to a filter paper on the chamber wall for evaporation. The ETHY and MeJA groups were exposed to treatments for the second time $12 \mathrm{~h}$ after the first exposure to the hormones, resulting in $24 \mathrm{~h}$ of treatment. Fruits were ripened in a $323 \mathrm{~L}$ chamber at $20 \pm 2{ }^{\circ} \mathrm{C}$ and $80 \pm 5 \%$ relative humidity in a 16-h day /8-h night cycle. Samples of 10 fruits from each replicate were taken at 4,10 , and 21 days after harvest (DAH), considering the control group as reference. The pericarp tissues of tomatoes were frozen in liquid nitrogen and stored at $-80{ }^{\circ} \mathrm{C}$ for further analysis. 


\subsection{Ethylene Emission}

Five fruits were placed in airtight glass containers $(600 \mathrm{~mL})$ at $25{ }^{\circ} \mathrm{C}$ for $1 \mathrm{~h}$. Five samples of $1 \mathrm{~mL}$ of gas produced in the headspace were collected with gastight syringes and injected into a gas chromatograph with a flame ionization detector (GC-FID; Agilent Technologies, Santa Clara, CA, USA, HP-6890) with HP-Plot Q column (30 m ×0.53 mm $\times$ $40 \mu \mathrm{m})$. The temperatures of the injector and detector were set at $250{ }^{\circ} \mathrm{C}$ and the oven at $30^{\circ} \mathrm{C}$. The helium gas flow was set at $1 \mathrm{~mL} \mathrm{~min}^{-1}$, and the injections were performed in pulsed splitless mode.

\subsection{Fruit Surface Color}

The colorimeter (HunterLab ColorQuest XE, Hunter Associates Laboratories, Sunset Hills Road, Reston, VA, USA) measured in terms of $L^{*}, a^{*}$, and $b^{*}$ space [34]. The fruit surface color was determined at the equatorial zone of six tomato fruits. The results were expressed as the hue angle.

\subsection{Metabolomic Analysis by GC-MS}

\subsubsection{Extraction and Derivatization of Polar Metabolites}

Frozen pericarp powder $(100 \mathrm{mg})$ was mixed with $100 \%$ distilled methanol at $-20{ }^{\circ} \mathrm{C}$ $(1400 \mu \mathrm{L})$ and ribitol $\left(200 \mu \mathrm{g} \mathrm{mL}{ }^{-1}\right.$, internal standard; $\left.60 \mu \mathrm{L}\right)$. The mixture was vortexed and centrifuged at $11,000 \times g$ for $10 \mathrm{~min}$. Chloroform at $-20{ }^{\circ} \mathrm{C}(750 \mu \mathrm{L})$ and Milli-Q water $(1500 \mu \mathrm{L})$ were added to the upper phase, followed by centrifugation at $2200 \mathrm{~g}$ for $15 \mathrm{~min}$. The upper hydrophilic phase $(150 \mu \mathrm{L})$ was dried under nitrogen gas. For derivatization, $20 \mathrm{mg} \mathrm{mL}^{-1}$ methoxyamine hydrochloride (Sigma-Aldrich Chemical Co., St. Louis, MO, USA; $40 \mu \mathrm{L}$ ) and pyridine were used. $N$-methyl- $N$-(trimethylsilyl) trifluoroacetamide (MSTFA; $70 \mu \mathrm{L}$ ) was added to the sample and incubated in an orbital shaker at $1000 \mathrm{~g}$ and $37^{\circ} \mathrm{C}$ for $30 \mathrm{~min}$ [35]. A pool of polar metabolite external standards (Sigma-Aldrich, Saint Louis, MO, USA) was applied: D-glucose, D-fructose, maltose, sucrose, D-galactose, myo-inositol, citric acid, L-alanine, L-serine, L-proline, L-aspartate, and L-glutamate [36].

\subsubsection{Extraction and Derivatization of Non-Polar Metabolites}

Frozen pericarp powder $(1000 \mathrm{mg})$ was mixed with chloroform $(1250 \mu \mathrm{L})$, methanol $(2500 \mu \mathrm{L}), n$-tridecane $\left(800 \mu \mathrm{g} \mathrm{mL}{ }^{-1}\right.$, internal standard; $\left.20 \mu \mathrm{L}\right)$. Then, $1.5 \%$ sodium sulfate $(1250 \mu \mathrm{L})$ and chloroform $(1250 \mu \mathrm{L})$ were added to the mixture, incubated on ice for $5 \mathrm{~min}$, and centrifuged at $4{ }^{\circ} \mathrm{C}$ and $1000 \mathrm{~g}$ for $15 \mathrm{~min}$. The upper polar phase was dried under nitrogen gas and redissolved in hexane $(1000 \mu \mathrm{L})$, toluene $(200 \mu \mathrm{L})$, methanol $(1500 \mu \mathrm{L})$, and $8 \%$ chloridric acid $(300 \mu \mathrm{L})$ and incubated for $1.5 \mathrm{~h}$ at $100{ }^{\circ} \mathrm{C}$. The hexane phase was dried under nitrogen gas, redissolved in hexane $(80 \mu \mathrm{L})$ and pyridine $(20 \mu \mathrm{L})$, and derivatized with MSTFA $(40 \mu \mathrm{L})$ [35-37]. A pool of fatty acid methyl ester external standards (Sigma-Aldrich, Saint Louis, MO, USA) was used: methyl laurate, methyl tetradecanoate, methyl palmitate, methyl octadecanoate, methyl arachidate, methyl docosanoate, methyl lignocerate, methyl linoleate, (Z)-9-oleyl methyl ester, methyl linolenate, and methyl palmitoleate [38].

\subsubsection{Gas Chromatography-Mass Spectrometry Analysis}

Derivatized pericarp samples were evaluated by GC-MS (Agilent GC-MS 5977, Agilent Technologies, Santa Clara, CA, USA) with an HP5ms column $(30 \mathrm{~m} \times 0.25 \mathrm{~m} \times 0.25 \mu \mathrm{m})$ [36]. Trimethylsilyl derivatives $(1 \mu \mathrm{L})$ were injected into an injector at $230{ }^{\circ} \mathrm{C}$ in splitless mode. The oven temperature ramp was $80^{\circ} \mathrm{C}$ (initial temperature), held for $2 \mathrm{~min}$, heated at $15^{\circ} \mathrm{C}$ $\min ^{-1}$ to $330^{\circ} \mathrm{C}$, and held for $6 \mathrm{~min}$. The electron impact ionization mass spectrometer was set at ionization voltage $70 \mathrm{eV}$, ion source temperature $250{ }^{\circ} \mathrm{C}$, injection port temperature $250{ }^{\circ} \mathrm{C}$, and mass scan range $70-600 \mathrm{~m} / \mathrm{z}$ at 20 scans s$^{-1}$. The flow rate of helium gas was $2 \mathrm{~mL} \mathrm{~min}^{-1}$. Experimental data were processed with Mass Hunter software (Agilent, Santa Clara, CA, USA) and validated using the NIST mass spectral library (NIST 2011, Gaithersburg, MD, USA). 


\subsubsection{HPLC Analysis of Carotenoids}

For the extraction of carotenoids, frozen pericarp powder (200 mg) was mixed with $100 \mu \mathrm{L}$ of $30 \% \mathrm{NaCl}(\mathrm{w}: \mathrm{v})$ solution and $200 \mu \mathrm{L}$ of dichloromethane. Hexane:diethyl ether $(1: 1 ; 500 \mu \mathrm{L})$ was added to the mixture and centrifuged $\left(13,000 \times g\right.$ at $4{ }^{\circ} \mathrm{C}$ for $\left.5 \mathrm{~min}\right)$ [39]. The upper phase was dried using nitrogen gas and redissolved in ethyl acetate. The HPLC (Infinity 1260 HPLC, Agilent Technologies, Santa Clara, CA, USA) was coupled to a diode array detector (DAD) equipped with a YMC Carotenoid HPLC C30 $(5 \mu \mathrm{m} \times 250 \mathrm{~mm} \times 4.6 \mathrm{~mm})$ column [40]. The carotenoid standards used were lycopene, $\beta$-carotene, and lutein (Sigma-Aldrich).

\subsection{Statistical Analysis}

Data were expressed as mean \pm standard deviation (SD) of four biological replicates. Statistical analysis was performed by ANOVA and Tukey's test $(p<0.05)$, using the Minitab 19.0 software package. Multivariate and fold change analyses were performed to evaluate the differences between treated and untreated groups using the Metaboanalyst 4.0 server [41]. Raw data were normalized by internal standard area, processed using log transformation $(\log 2)$, mean-centered, and divided by the square root of the deviation of each variable (Pareto scaling).

\section{Conclusions}

All these metabolite changes observed during treatment with phytohormone are extremely relevant to studying the fruit quality of tomatoes. However, most of the detected metabolite changes were associated with the sensory and nutritional value, improved by increasing primary and secondary metabolites, respectively. Exogenous methyl jasmonate impacted the profiles of amino acids, fatty acids, tocopherols, and phytosterols by increasing their levels during ripening off-the-vine. Glutamine, glutamic acid, GABA, tryptophan, phenylalanine, and tyrosine were increased by methyl jasmonate, mainly at $10 \mathrm{DAH}$. Among the fatty acids, oleic, linoleic, and linolenic acids were significantly affected by the methyl jasmonate, increasing their levels by up to four-fold compared with CTRL. Additionally, methyl jasmonate significantly increased the accumulation of $\alpha$-tocopherol and $\beta$-sitosterol in fully ripe fruits. Thus, our results suggest that methyl jasmonate can be used as a tool to contribute to sensory attributes by increasing amino acids and fatty acids, which play an important role in the precursors of volatile compounds and the taste of fruits. Methyl jasmonate also improves the nutritional value of fruits by increasing the accumulation of tocopherols and phytosterols, which are related to health benefits.

Supplementary Materials: The following supporting information can be downloaded at: https: / / www.mdpi.com/article/10.3390/plants11030366/s1, Table S1: Primary metabolites in tomato (Solanum lycopersicum L. cv. Grape) treated with ethylene (ETHY) and methyl jasmonate (MeJA) compared to control group (CTRL) detected by gas chromatography-mass spectrometry (GC-MS); Table S2: Carotenoids contents ( $\mu \mathrm{g} . \mathrm{g}^{-1} \mathrm{FW}$ ) in tomato (Solanum lycopersicum L. cv. Grape) fruits exposed to ethylene (ETHY) and methyl jasmonate (MeJA) treatments at 04, 10 and 21 days after harvest (DAH) detected by high performance liquid chromatography (HPLC); Table S3: Tocopherols and phytosterols in tomato (Solanum lycopersicum L. cv. Grape) fruits exposed to ethylene (ETHY) and methyl jasmonate (MeJA) treatments at 04, 10 and 21 days after harvest (DAH) detected by gas chromatography-mass spectrometry (GC-MS).

Author Contributions: Investigation, Writing and Original draft preparation: S.L.R.M.; WritingReview and Editing: E.d.C.T.; Methodology, Software: G.B.P. and H.C.R.M.; Data curation: I.L.M.; Supervision: E.P. All authors have read and agreed to the published version of the manuscript.

Funding: This research was funded by the São Paulo Research Foundation (FAPESP, Grant 2013/07914-8) and Coordination for the Improvement of Higher Education Personnel (CAPES, Grant 88882.376974/2018-01).

Informed Consent Statement: Not applicable.

Acknowledgments: The authors gratefully acknowledge the financial support. The authors also thank T.M. Shiga, A. de Oliveira, L.F.L. Macedo and L.H.J. da Silva for the technical assistance. 
Conflicts of Interest: The authors declare no conflict of interest.

\section{References}

1. Raiola, A.; Rigano, M.M.; Calafiore, R.; Frusciante, L.; Barone, A. Enhancing the Health-Promoting Effects of Tomato Fruit for Biofortified Food. Mediat. Inflamm. 2014, 2014, 139873. [CrossRef] [PubMed]

2. Quinet, M.; Angosto, T.; Yuste-Lisbona, F.J.; Blanchard-Gros, R.; Bigot, S.; Martinez, J.-P.; Lutts, S. Tomato Fruit Development and Metabolism. Front. Plant Sci. 2019, 10, 1554. [CrossRef] [PubMed]

3. Chen, H.; Jones, A.D.; Howe, G.A. Constitutive activation of the jasmonate signaling pathway enhances the production of secondary metabolites in tomato. FEBS Lett. 2006, 580, 2540-2546. [CrossRef] [PubMed]

4. Efreschi, L. Nitric oxide and phytohormone interactions: Current status and perspectives. Front. Plant Sci. 2013, 4, 398. [CrossRef]

5. Chu-Puga, Á.; González-Gordo, S.; Rodríguez-Ruiz, M.; Palma, J.M.; Corpas, F.J. NADPH Oxidase (Rboh) Activity is Up Regulated during Sweet Pepper (Capsicum annuum L.) Fruit Ripening. Antioxidants 2019, 8, 9. [CrossRef]

6. Palma, J.M.; Freschi, L.; Ruiz, M.R.; González-Gordo, S.; Corpas, F.J. Nitric oxide in the physiology and quality of fleshy fruits. J. Exp. Bot. 2019, 70, 4405-4417. [CrossRef]

7. Eum, H.L.; Kim, H.B.; Choi, S.B.; Lee, S.K. Regulation of ethylene biosynthesis by nitric oxide in tomato (Solanum lycopersicum L.) fruit harvested at different ripening stages. Eur. Food Res. Technol. 2008, 228, 331-338. [CrossRef]

8. Bodanapu, R.; Gupta, S.K.; Basha, P.O.; Sakthivel, K.; Sreelakshmi, Y.; Sharma, R. Nitric Oxide Overproduction in Tomato shr Mutant Shifts Metabolic Profiles and Suppresses Fruit Growth and Ripening. Front. Plant Sci. 2016, 7, 1714. [CrossRef]

9. Saito, N.; Yoshimasa, N.; Mori, I.C.; Murata, Y.; Nakamura, Y. Nitric oxide functions in both methyl jasmonate signaling and abscisic acid signaling in Arabidopsis guard cells. Plant Signal. Behav. 2009, 4, 119-120. [CrossRef]

10. Tao, X.; Wu, Q.; Li, J.; Wang, D.; Nassarawa, S.S.; Ying, T. Ethylene biosynthesis and signal transduction are enhanced during accelerated ripening of postharvest tomato treated with exogenous methyl jasmonate. Sci. Hortic. 2021, 281, 109965. [CrossRef]

11. Fan, X.; Mattheis, J.P.; Fellman, J.K. A role for jasmonates in climacteric fruit ripening. Planta 1998, 204, 444-449. [CrossRef]

12. Yu, M.; Shen, L.; Zhang, A.; Sheng, J. Methyl jasmonate-induced defense responses are associated with elevation of 1aminocyclopropane-1-carboxylate oxidase in Lycopersicon esculentum fruit. J. Plant Physiol. 2011, 168, 1820-1827. [CrossRef] [PubMed]

13. Wang, S.-Y.; Shi, X.-C.; Liu, F.-Q.; Laborda, P. Effects of exogenous methyl jasmonate on quality and preservation of postharvest fruits: A review. Food Chem. 2021, 353, 129482. [CrossRef] [PubMed]

14. Ho, T.-T.; Murthy, H.N.; Park, S.-Y. Methyl Jasmonate Induced Oxidative Stress and Accumulation of Secondary Metabolites in Plant Cell and Organ Cultures. Int. J. Mol. Sci. 2020, 21, 716. [CrossRef]

15. Liu, H.; Meng, F.; Miao, H.; Chen, S.; Yin, T.; Hu, S.; Shao, Z.; Liu, Y.; Gao, L.; Zhu, C.; et al. Effects of postharvest methyl jasmonate treatment on main health-promoting components and volatile organic compounds in cherry tomato fruits. Food Chem. 2018, 263, 194-200. [CrossRef]

16. Meza, S.R.; Tobaruela, E.D.C.; Pascoal, G.B.; Massaretto, I.L.; Purgatto, E. Post-Harvest Treatment with Methyl Jasmonate Impacts Lipid Metabolism in Tomato Pericarp (Solanum lycopersicum L. cv. Grape) at Different Ripening Stages. Foods 2021, $10,877$. [CrossRef]

17. Pott, D.M.; Vallarino, J.G.; Osorio, S. Metabolite Changes during Postharvest Storage: Effects on Fruit Quality Traits. Metabolites 2020, 10, 187. [CrossRef]

18. Almeida, J.; Asís, R.; Molineri, V.N.; Sestari, I.; Lira, B.S.; Carrari, F.; Peres, L.E.P.; Rossi, M. Fruits from ripening impaired, chlorophyll degraded and jasmonate insensitive tomato mutants have altered tocopherol content and composition. Phytochemistry 2015, 111, 72-83. [CrossRef]

19. Moreau, R.A.; Nyström, L.; Whitaker, B.D.; Winkler-Moser, J.K.; Baer, D.J.; Gebauer, S.K.; Hicks, K.B. Phytosterols and their derivatives: Structural diversity, distribution, metabolism, analysis, and health-promoting uses. Prog. Lipid Res. 2018, 70, 35-61. [CrossRef]

20. Wang, C.; Xing, J.; Chin, C.-K.; Ho, C.-T.; Martin, C.E. Modification of fatty acids changes the flavor volatiles in tomato leaves. Phytochemistry 2001, 58, 227-232. [CrossRef]

21. Zhang, Y.; Pan, Z.; Venkitasamy, C.; Ma, H.; Li, Y. Umami taste amino acids produced by hydrolyzing extracted protein from tomato seed meal. LWT 2015, 62, 1154-1161. [CrossRef]

22. Liu, L.; Wei, J.; Zhang, M.; Zhang, L.; Li, C.; Wang, Q. Ethylene independent induction of lycopene biosynthesis in tomato fruits by jasmonates. J. Exp. Bot. 2012, 63, 5751-5761. [CrossRef] [PubMed]

23. Beauvoit, B.; Belouah, I.; Bertin, N.; Cakpo, C.B.; Colombié, S.; Dai, Z.; Gautier, H.; Génard, M.; Moing, A.; Roch, L.; et al. Putting primary metabolism into perspective to obtain better fruits. Ann. Bot. 2018, 122, 1-21. [CrossRef] [PubMed]

24. Zuccarelli, R.; Rodríguez-Ruiz, M.; Lopes-Oliveira, P.J.; Pascoal, G.B.; Andrade, S.C.S.; Furlan, C.M.; Purgatto, E.; Palma, J.M.; Corpas, F.J.; Rossi, M.; et al. Multifaceted roles of nitric oxide in tomato fruit ripening: NO-induced metabolic rewiring and consequences for fruit quality traits. J. Exp. Bot. 2020, 72, 941-958. [CrossRef] [PubMed]

25. Takayama, M.; Eezura, H. How and why does tomato accumulate a large amount of GABA in the fruit? Front. Plant Sci. 2015, 6, 612. [CrossRef] 
26. Massaretto, I.; Albaladejo, I.; Purgatto, E.; Flores, F.B.; Plasencia, F.; Egea-Fernández, J.M.; Bolarin, M.C.; Egea, I. Recovering Tomato Landraces to Simultaneously Improve Fruit Yield and Nutritional Quality Against Salt Stress. Front. Plant Sci. 2018, 9, 1778. [CrossRef]

27. Moro, L.; Da Ros, A.; Da Mota, R.V.; Purgatto, E.; Mattivi, F.; Arapitsas, P. LC-MS untargeted approach showed that methyl jasmonate application on Vitis labrusca L. grapes increases phenolics at subtropical Brazilian regions. Metabolomics 2020, 16, 18. [CrossRef]

28. Li, T.; Xu, Y.; Zhang, L.; Ji, Y.; Tan, D.; Yuan, H.; Wang, A. The Jasmonate-Activated Transcription Factor MdMYC2 Regulates ETHYLENE RESPONSE FACTOR and Ethylene Biosynthetic Genes to Promote Ethylene Biosynthesis during Apple Fruit Ripening. Plant Cell 2017, 29, 1316-1334. [CrossRef]

29. Srivastava, A.; Handa, A.K. Hormonal regulation of tomato fruit development: A molecular perspective. J. Plant Growth Regul. 2005, 24, 67-82. [CrossRef]

30. Barry, C.S.; Giovannoni, J.J. Ethylene and Fruit Ripening. J. Plant Growth Regul. 2007, 26, 143-159. [CrossRef]

31. Concha, C.M.; Figueroa, N.E.; Poblete, L.A.; Oñate, F.J.; Schwab, W.; Figueroa, C. Methyl jasmonate treatment induces changes in fruit ripening by modifying the expression of several ripening genes in Fragaria chiloensis fruit. Plant Physiol. Biochem. 2013, 70, 433-444. [CrossRef] [PubMed]

32. Saniewski, M.; Czapski, J. Stimulatory effect of methyl jasmonate on the ethylene production in tomato fruits. Experientia 1985, 41, 256-257. [CrossRef]

33. Saniewski, M.; Nowacki, J.; Czapski, J. The Effect of Methyl Jasmonate on Ethylene Production and Ethylene-Forming Enzyme Activity in Tomatoes. J. Plant Physiol. 1987, 129, 175-180. [CrossRef]

34. Fabi, J.P.; Cordenunsi, B.R.; Barreto, G.P.D.M.; Mercadante, A.Z.; Lajolo, F.M.; Nascimento, J.R.O.D. Papaya Fruit Ripening: Response to Ethylene and 1-Methylcyclopropene (1-MCP). J. Agric. Food Chem. 2007, 55, 6118-6123. [CrossRef]

35. Lisec, J.; Schauer, N.; Kopka, J.; Willmitzer, L.; Fernie, A.R. Gas chromatography mass spectrometry-based metabolite profiling in plants. Nat. Protoc. 2006, 1, 387-396. [CrossRef]

36. Kind, T.; Wohlgemuth, G.; Lee, D.Y.; Lu, Y.; Palazoglu, M.; Shahbaz, S.; Fiehn, O. FiehnLib: Mass Spectral and Retention Index Libraries for Metabolomics Based on Quadrupole and Time-of-Flight Gas Chromatography/Mass Spectrometry. Anal. Chem. 2009, 81, 10038-10048. [CrossRef]

37. Bligh, E.G.; Dyer, W.J. A rapid method of total lipid extraction and purification. Can. J. Biochem. Physiol. 1959, 37, 911-917. [CrossRef]

38. Ichihara, K.; Fukubayashi, Y. Preparation of fatty acid methyl esters for gas-liquid chromatography. J. Lipid Res. 2010, 51, 635-640. [CrossRef]

39. Seé1;rino, S.; Gomez, L.; Costagliola, G.; Gautier, H. HPLC Assay of Tomato Carotenoids: Validation of a Rapid Microextraction Technique. J. Agric. Food Chem. 2009, 57, 8753-8760. [CrossRef]

40. Souza, M.A.D.S.; Peres, L.; Freschi, J.R.; Purgatto, E.; Lajolo, F.M.; Hassimotto, N.M.A. Changes in flavonoid and carotenoid profiles alter volatile organic compounds in purple and orange cherry tomatoes obtained by allele introgression. J. Sci. Food Agric. 2019, 100, 1662-1670. [CrossRef]

41. Chong, J.; Soufan, O.; Li, C.; Caraus, I.; Li, S.; Bourque, G.; Wishart, D.S.; Xia, J. MetaboAnalyst 4.0: Towards more transparent and integrative metabolomics analysis. Nucleic Acids Res. 2018, 46, W486-W494. [CrossRef] [PubMed] 